\title{
Influence of Temperature and Proportion on Mechanism of Hectorite by Hydrothermal Synthesis
}

\author{
Su-Yan TIAN ${ }^{1, a}$, Jun MA ${ }^{1, b}$, Rong-Jian YING ${ }^{1, c}$ Shao-Lei XIE ${ }^{2, d}$ Shan-Liang \\ $\mathrm{MU}^{1, \mathrm{e}, *}$ \\ ${ }^{1}$ School of Chemistry and Chemical Engineering, Linyi University, 276000, China \\ ${ }^{2}$ Key Laboratory of Comprehensive and Highly Efficient Utilization of Salt Lake Resources, Chinese \\ Academy of Sciences, 810008, China

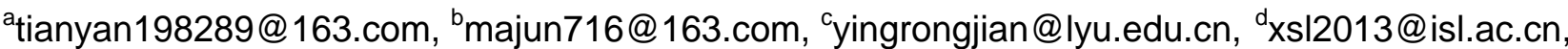 \\ echem@lyu.edu.cn \\ * Shan-Liang MU
}

Keywords: Hectorite, Hydrothermal reaction, Mechanism, synthesis process.

\begin{abstract}
The properties of hectorite was strongly affected by their microstructures and purity. Here $\mathrm{Na}_{\mathrm{x}} \mathrm{Li}_{\mathrm{x}} \mathrm{Mg}_{3-\mathrm{x}} \mathrm{Si}_{4} \mathrm{O}_{10}(\mathrm{OH})_{2} \cdot 4 \mathrm{H}_{2} \mathrm{O}$ multilayer pancakelike structures were fabricated successfully by hydrothermal reaction of $\mathrm{Na}_{2} \mathrm{SiO}_{3} \cdot 9 \mathrm{H}_{2} \mathrm{O}, \mathrm{MgCl}_{2} \cdot 6 \mathrm{H}_{2} \mathrm{O}$ and $\mathrm{LiCl} \cdot \mathrm{H}_{2} \mathrm{O}$ in autoclave at $473 \mathrm{~K}$. The synthesis process of hectorite were observed by XRD. The formation mechanism of $\mathrm{Na}_{x} \mathrm{Li}_{\mathrm{x}} \mathrm{Mg}_{3-\mathrm{x}} \mathrm{Si}_{4} \mathrm{O}_{10}(\mathrm{OH})_{2} \cdot 4 \mathrm{H}_{2} \mathrm{O}$ was discussed. The influence of temperature and proportion reactants to hectorite were proposed. The amorphous hectorite was formed firstly. Then the hectortie particles aggregated and oriented assembly with the help of reaction temperature. The effected of proportion of reactants such as molar fraction of $\mathrm{LiCl}$ and the $\mathrm{Mg} / \mathrm{Si}$ molar ratio were discussed. The purity of hectorite changed regularly with different $\mathrm{Mg} / \mathrm{Si}$ molar ratio.
\end{abstract}

\section{Introduction}

It is well-known that the properties of materials are closed related with their purity and microstructures. The little change of purity and microstructures make the properties of one substance change drastically. Therefore, increasing attention was attracted to fabricate materials with different microstructure, and research the mechanism of synthesis process in recent years [1].Hectorite was a class of phyllosilicates which usually from as a result of chemical weathering of other silicate minerals at the surface of the earth. Hectorite belongs to the same general family of 2:1 layered. The crystal structure consists of layers made up of two tetrahedral coordinated silicon atoms fused to an edge-shared octahedral sheet of magnesium hydroxide. Isomorphic substitution within the layers, for example, $\mathrm{Mg}^{2+}$ replaced by $\mathrm{Li}^{+}$, generates negative charges that counterbalanced by alkali cations situated inside the galleries [2].

Depending on the layer structure and specific properties, for example high specific surface area, ion exchange capacity and hydration property, hectorite was widely used in many important fields, such as catalysis [3], synthesis of polymer-based nanostructured materials [4], adsorption [5], and environmental issues [6]. Many studies were carried out to investigate the synthesis of pure hecorite. Zhou et al. [7] evaluated the influences of synthesis parameters such as crystallization time, hydrothermal temperature and reactant ration on the structure development of hectorite. The crystallinity of hectorite increased with increasing crystallization temperature. Isabel Vicente et al. [8] reported fast microwave synthesis of hectorite. The effect of brucite used, aging temperature, time under microwaves on the resulting hectorite were researched. The hydrothermal microwave treatment provides a faster synthesis of hectorite.

In our previous research, hectorite and its composite was synthesized, and its performances were also conformed [9-12]. However, the mechanism and synthesis process were few researched. In this paper, the influence of temperature and proportion on mechanism of hectorite were discussed. The research results are very important for the preparation and application of high purity hectorite. 


\section{Materials and Methods}

\subsection{Materials}

In this paper, the starting materials are magnesium chloride $\left(\mathrm{MgCl}_{2} \cdot 6 \mathrm{H}_{2} \mathrm{O}\right)$, lithium chloride $\left(\mathrm{LiCl} \cdot \mathrm{H}_{2} \mathrm{O}\right)$ and sodium silicate $\left(\mathrm{Na}_{2} \mathrm{SiO}_{3} \cdot 9 \mathrm{H}_{2} \mathrm{O}\right)$. Silica was added in the form of $\mathrm{Na}_{2} \mathrm{SiO}_{3} \cdot 9 \mathrm{H}_{2} \mathrm{O}$ supplied by Tianjin Hongyan Chemical Reagent Factory. $\mathrm{MgCl}_{2} \cdot 6 \mathrm{H}_{2} \mathrm{O}$ supplied by Tianjin Kermel Chemical Reagent Factory was used as the source of $\mathrm{Mg}$. The source of $\mathrm{Li}$ was $\mathrm{LiCl} \cdot \mathrm{H}_{2} \mathrm{O}$ supplied by Shanghai Chemical Reagent General Factory. All the reagents were reagent grade and used without any further purification.

\subsection{Experimental and Method}

Three starting reagents were weighed out in the appropriate proportions and de-ionized water was added. Each sample was mixed by hand and loaded into high pressure polytetrafluoroethylene (PTFE) reaction autoclave, which were heated at different temperature and left to equilibrate for 20 hours. The product was centrifuged and dried at $353 \mathrm{~K}$.

\subsection{Instrumentation}

The samples were detected by X-ray diffraction (XRD) analysis using a Shimadzu 6000X X-ray diffractometer with $\mathrm{Cu} \mathrm{K} \alpha$ radiation. All samples were scanned over a $3 \sim 80^{\circ} 2 \theta$ range using a step size of 0.00170 with a $1 \mathrm{~s}$ step rate.

Scanning electron microscope (SEM) images were taken using JSM-5610LV,. The samples were firstly dispersed in ethanol, dried in air and then coated with gold before observation of SEM.

\section{Results and Discussion}

In the process of hydrothermal synthesis hectorite, water $\left(\mathrm{H}_{2} \mathrm{O}\right)$ was used as solvent. The effect of $\mathrm{H}_{2} \mathrm{O}$ Phase was neglected. However, the mechanism and the process were influenced by reaction temperature and the proportion of reactants. The proportion of reactants were listed in Table 1.

Table 1 The proportion of reactants used to synthesize hectorite

\begin{tabular}{|l|l|l|l|}
\hline \multirow{2}{*}{ Sample number } & \multicolumn{3}{|c|}{ Mol\% in reactants } \\
\cline { 2 - 4 } & $\mathrm{Na}_{2} \mathrm{SiO}_{3} \cdot 9 \mathrm{H}_{2} \mathrm{O}$ & $\mathrm{MgCl}_{2} \cdot 6 \mathrm{H}_{2} \mathrm{O}$ & $\mathrm{LiCl}$ \\
\hline $1 \#$ & 50.00 & 50.00 & 0 \\
\hline $2 \#$ & 37.50 & 62.50 & 0 \\
\hline $3 \#$ & 53.57 & 40.18 & 6.25 \\
\hline $4 \#$ & 46.875 & 46.875 & 6.25 \\
\hline $5 \#$ & 43.75 & 50.00 & 6.25 \\
\hline $6 \#$ & 40.18 & 53.57 & 6.25 \\
\hline $7 \#$ & 37.50 & 56.25 & 6.25 \\
\hline $8 \#$ & 35.16 & 58.59 & 6.25 \\
\hline $9 \#$ & 32.18 & 61.57 & 6.25 \\
\hline $10 \#$ & 42.00 & 45.50 & 12.50 \\
\hline $11 \#$ & 39.77 & 47.73 & 12.50 \\
\hline $12 \#$ & 35.00 & 52.50 & 12.50 \\
\hline $13 \#$ & 37.27 & 44.73 & 18.00 \\
\hline $14 \#$ & 36.00 & 39.00 & 25.00 \\
\hline $15 \#$ & 33.795 & 41.205 & 25.00 \\
\hline $16 \#$ & 46.86 & 35.14 & 18.00 \\
\hline $17 \#$ & 42.86 & 32.14 & 25.00 \\
\hline $18 \#$ & 31.43 & 23.57 & 45.00 \\
\hline $19 \#$ & 33.33 & 66.67 & 0 \\
\hline $20 \#$ & 29.17 & 58.33 & 12.50 \\
\hline $21 \#$ & 16.67 & 33.33 & 50.00 \\
\hline $22 \#$ & 15.00 & 30.00 & 55.00 \\
\hline
\end{tabular}




\subsection{Effect of Reaction Temperature}

The mechanism and the process of synthesis hectorite were influenced by the reaction temperature. In this process, the sample 6\# was researched at ambient temperature. The means of the duplicated experimental results are plotted in Fig. 1. From Fig. 1, it can be seen that in the $\mathrm{Na}_{2} \mathrm{SiO}_{3}-\mathrm{MgCl}_{2}-\mathrm{LiCl}-$ $\mathrm{H}_{2} \mathrm{O}$ system, only $\mathrm{SiO}_{3}{ }^{2-}$ reacted with $\mathrm{Mg}^{2+}$ and the amorphous sediment $\mathrm{MgSiO}_{3}$ was obtained at ambient temperature (Fig.1 a). After calcination, the characteristic diffraction of $\mathrm{MgSiO}_{3} \mathrm{wa}_{\mathrm{s}}$ observed (Fig.1 b).

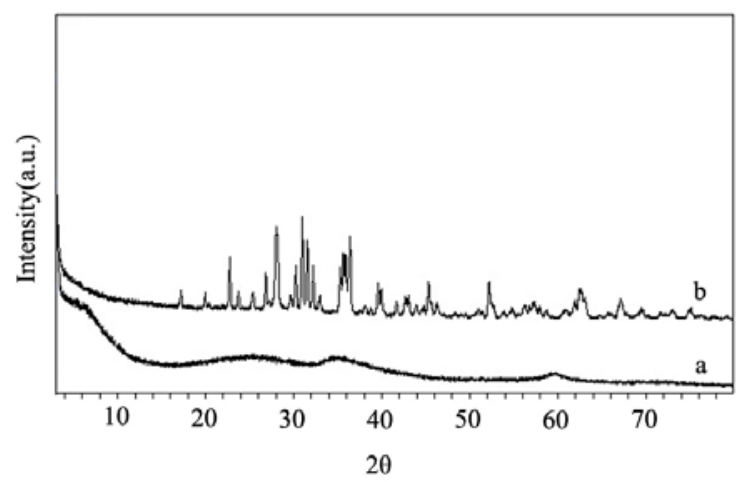

Fig. 1 The XRD pattern of sample 6\# at ambient temperature (a, without calcination; b, with calcination at $800^{\circ} \mathrm{C}$ )

Compared with the chemical reaction at ambient temperature, the synthesis process and mechanism with hydrothermal method were researched. According to proportion of reactants (6\#), the react was carried out in autoclave. The temperature of reaction increased from $423 \mathrm{~K}$ to $463 \mathrm{~K}$. The means of the duplicated experimental data are depicted in Fig.2. Two obvious changes were observed. Firstly, according to the XRD pattern of sample 6\#, in hydrothermal condition, $\mathrm{Mg}_{4} \mathrm{Si}_{4} \mathrm{O}_{10}(\mathrm{OH})_{4} \cdot 2 \mathrm{H}_{2} \mathrm{O}$ and $\mathrm{Na}_{\mathrm{x}} \mathrm{Mg}_{3-\mathrm{x}} \mathrm{Li}_{\mathrm{x}} \mathrm{Si}_{4} \mathrm{O}_{10}(\mathrm{OH})_{2} \cdot 4 \mathrm{H}_{2} \mathrm{O}$ (hectorite) were obtained. The chemical reactions were showed in Formula (1) and Formula(2). The results were consist with our previously studies [10]. Secondly, the characteristic diffraction of $\mathrm{Mg}(\mathrm{OH})_{2}$ was observed within temperature ranging from $423 \mathrm{~K}$ to $453 \mathrm{~K}$. With the increment of temperature, the intensity of the characteristic diffraction decreased. When the temperature increased to $463 \mathrm{~K}$, the characteristic diffraction of $\mathrm{Mg}(\mathrm{OH})_{2}$ disappeared. This changes were showed in Formula (3). The characteristic diffraction of $\mathrm{Mg}(\mathrm{OH})_{2}$ disappeared in XRD pattern (Fig.2).

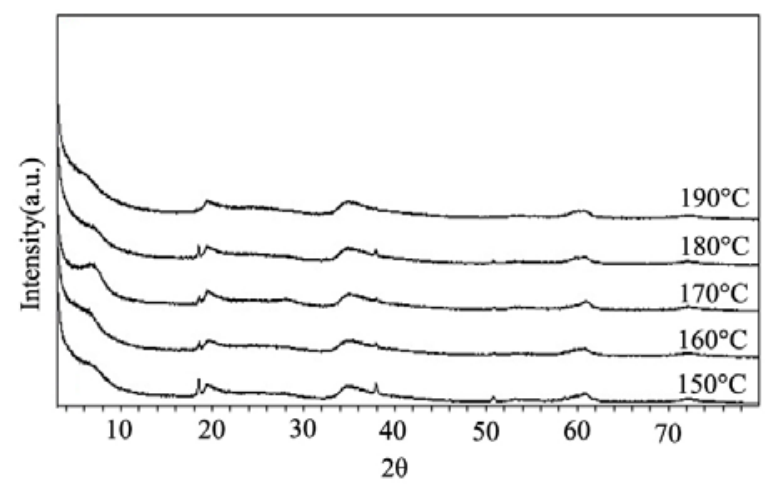

Fig.2 The XRD pattern of sample 6\# at different temperature

$$
\begin{gathered}
\quad 4 \mathrm{Na}_{2} \mathrm{SiO}_{3}+4 \mathrm{MgCl}_{2}+4 \mathrm{H}_{2} \mathrm{O} \rightarrow \mathrm{Mg}_{4} \mathrm{Si}_{4} \mathrm{O}_{10}(\mathrm{OH})_{4} \cdot 2 \mathrm{H}_{2} \mathrm{O}+8 \mathrm{NaCl} \\
4 \mathrm{Na}_{2} \mathrm{SiO}_{3}+3 \mathrm{MgCl}_{2}+\mathrm{xLiCl}+6 \mathrm{H}_{2} \mathrm{O} \rightarrow \mathrm{Na}_{x} \mathrm{Mg}_{3-\mathrm{x}} \mathrm{Li}_{\mathrm{x}} \mathrm{Si}_{4} \mathrm{O}_{10}(\mathrm{OH})_{2} \cdot 4 \mathrm{H}_{2} \mathrm{O} \\
+(6+\mathrm{x}) \mathrm{NaCl}+\mathrm{xMg}(\mathrm{OH})_{2}+(2-2 \mathrm{x}) \mathrm{NaOH}
\end{gathered}
$$




$$
\begin{aligned}
& \mathrm{xMg}(\mathrm{OH})_{2}+\mathrm{Na}_{\mathrm{x}} \mathrm{Mg}_{3-\mathrm{x}} \mathrm{Li}_{\mathrm{x}} \mathrm{Si}_{4} \mathrm{O}_{10}(\mathrm{OH})_{2} \cdot 4 \mathrm{H}_{2} \mathrm{O} \rightarrow \mathrm{Mg}_{4} \mathrm{Si}_{4} \mathrm{O}_{10}(\mathrm{OH})_{4} \cdot 2 \mathrm{H}_{2} \mathrm{O} \\
& +\mathrm{xNaOH}+\mathrm{xLiOH}
\end{aligned}
$$

\subsection{Effect of Proportions of Reactants}

The synthesis process of hectorite was influenced by the proportions of reactants. With different proportions, the constitution of product was different absolutely. The samples of 19\#, 20\#, 21\#, 22\# were researched at 453K. The results were showed in Fig.3. The Mg/Si molar ratio of the samples 19\#, 20\#, 21\#, 22\# were 2:1, but the molar fraction of Li was increased from sample 19\# to 22\#. According to the XRD pattern of the samples, only the characteristic diffraction of $\mathrm{Mg}_{4} \mathrm{Si}_{4} \mathrm{O}_{10}(\mathrm{OH})_{4} \cdot 2 \mathrm{H}_{2} \mathrm{O}$ were observed. In these samples, the content of $\mathrm{Mg}$ was excess, the $\mathrm{SiO}_{3}{ }^{2-}$ reacted with $\mathrm{Mg}^{2+}$ absolutely, and the spare of $\mathrm{Mg}^{2+}$ was washed when the sample was divided by centrifugation. Because of the excess content of $\mathrm{Mg}$, in $\mathrm{Mg}_{4} \mathrm{Si}_{4} \mathrm{O}_{10}(\mathrm{OH})_{4} \cdot 2 \mathrm{H}_{2} \mathrm{O}$ crystal structure, $\mathrm{Mg}^{2+}$ was replaced by $\mathrm{Li}^{+}$hardly. The reactant $\mathrm{LiCl}$ did not react with other reactants, and also washed in the centrifugation process.

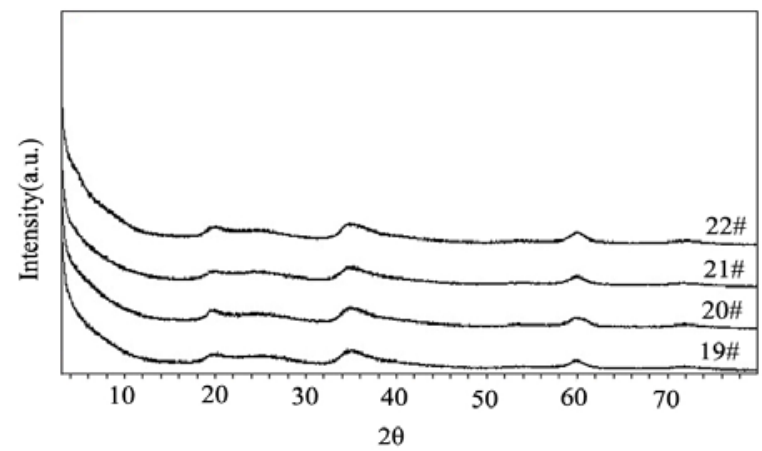

Fig. 3 The XRD pattern of the samples 19\#, 20\#, 21\#, 22\# ( the Mg/Si molar ratio was 2:1)

When the molar fraction of $\mathrm{Mg}$ decreased, the hectorite phase was observed and the $\mathrm{Mg}_{4} \mathrm{Si}_{4} \mathrm{O}_{10}(\mathrm{OH})_{4} \cdot 2 \mathrm{H}_{2} \mathrm{O}$ phase disappeared, which were showed in Fig.4. The Mg/Si molar ratio of the samples 3\#,16\#, 17\#,18\# were 1:1.333, but the molar fraction of Li was increased from sample 3\# to 18\#. From Fig. 4, it can be seen the characteristic diffraction of hectorite (001) and $\mathrm{Li}_{2} \mathrm{SiO}_{3}$. With the increment of $\mathrm{LiCl}$ molar fraction, the intensity of $\mathrm{Li}_{2} \mathrm{SiO}_{3}$ characteristic diffraction also increased. These results can be attributed to the excess of $\mathrm{Na}_{2} \mathrm{SiO}_{3}$. When the $\mathrm{Mg} / \mathrm{Si}$ molar ratio of the reactants were 1:1.333, the $\mathrm{Mg}^{2+}$ reacted with $\mathrm{SiO}_{3}{ }^{2-}$ absolutely and the hectorite phase was obtained. In this condition, $\mathrm{Mg}$ of the hectorite crystal structure was easily replaced by $\mathrm{Li}$. Meanwhile, the spare of $\mathrm{Li}^{+}$ reacted with the spare $\mathrm{SiO}_{3}{ }^{2-}$, and the $\mathrm{Li}_{2} \mathrm{SiO}_{3}$ phase was obtained.

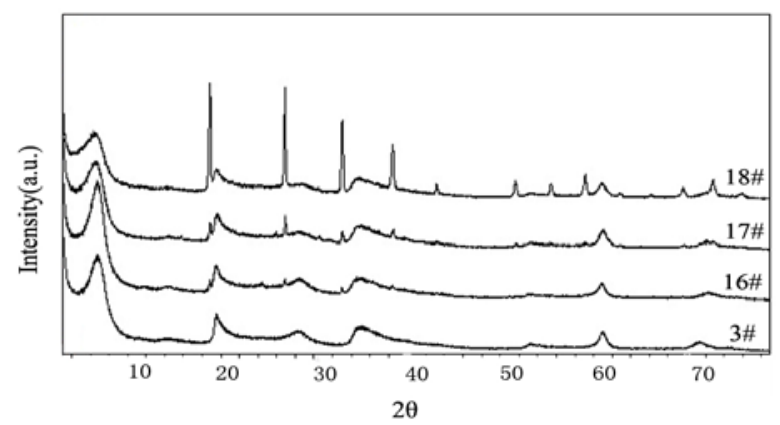

Fig. 4 The XRD pattern of the samples 3\#, 16\#, 17\#, 18\# (the Mg/Si molar ratio was 1:1.333)

The process of synthesis hectorite also was influenced by $\mathrm{Mg} / \mathrm{Si}$ molar ratio of the reactants. The means of the duplicated experimental data are depicted in Fig.5 and Fig.6. In Fig.5, the reaction system was $\mathrm{MgCl}_{2}-\mathrm{Na}_{2} \mathrm{SiO}_{3}$ binary system. The $\mathrm{Mg} / \mathrm{Si}$ molar ratio of samples $1 \#, 2 \#$ and 19\# were 1:1, 1.667: 1 and 2:1 respectively. Based on data illustrated in Fig.5, with the $\mathrm{Mg} / \mathrm{Si}$ molar ratio 
increased, the constitution of the product changed obviously. In the sample $1 \#$, the product was the mixture of $\mathrm{Mg}_{4} \mathrm{Si}_{4} \mathrm{O}_{10}(\mathrm{OH})_{4} \cdot 2 \mathrm{H}_{2} \mathrm{O}$ phase and the $\mathrm{Mg}_{3} \mathrm{Si}_{4} \mathrm{O}_{10}(\mathrm{OH})_{2} \cdot 4 \mathrm{H}_{2} \mathrm{O}$ phase. With increment of $\mathrm{Mg} / \mathrm{Si}$ molar ratio, the content of $\mathrm{Mg}_{3} \mathrm{Si}_{4} \mathrm{O}_{10}(\mathrm{OH})_{2} \cdot 4 \mathrm{H}_{2} \mathrm{O}$ phase decreased but the $\mathrm{Mg}_{4} \mathrm{Si}_{4} \mathrm{O}_{10}(\mathrm{OH})_{4} \cdot 2 \mathrm{H}_{2} \mathrm{O}$ phase increased. When the $\mathrm{Mg} / \mathrm{Si}$ molar ratio was 2:1, the product was $\mathrm{Mg}_{4} \mathrm{Si}_{4} \mathrm{O}_{10}(\mathrm{OH})_{4} \cdot 2 \mathrm{H}_{2} \mathrm{O}$ phase only.

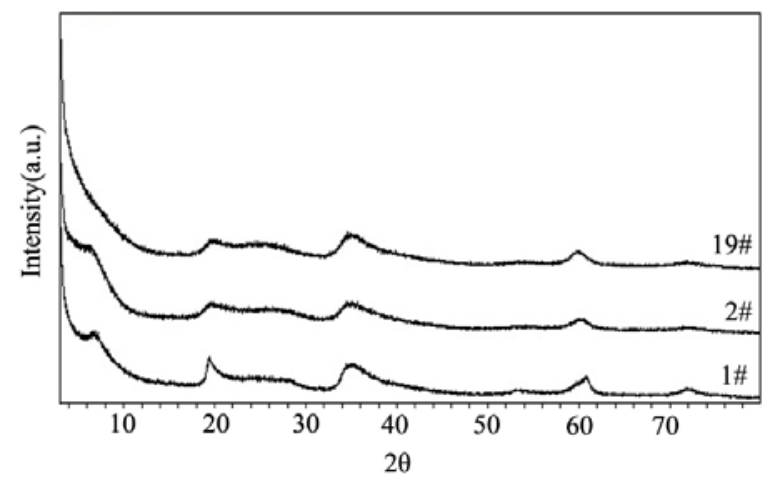

Fig. 5 The XRD pattern of the samples 1\#, 2\#, 19\# (The content of Li was 0; the $\mathrm{Mg} / \mathrm{Si}$ molar ratio of 1\#, 2\#, 19\# was 1:1, 1.667:1 and 2:1)

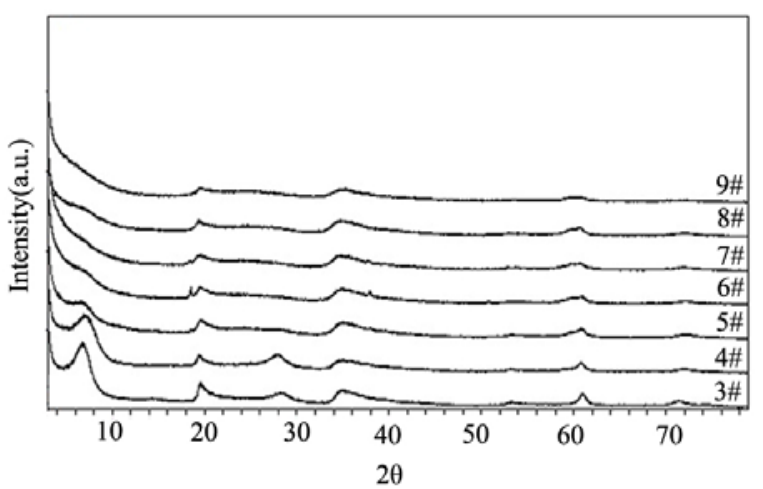

Fig. 6 The XRD pattern of the samples 3\#, 4\#, 5\#, 6\#, 7\#, 8\#, 9\# (The molar fraction of Li was 6.25\%; the $\mathrm{Mg} / \mathrm{Si}$ molar ratio was $0.750: 1,1: 1,1.143: 1,1.333: 1,1.5: 1,1.666: 1,1.913: 1$ respectively)

In Fig. 6, the $\mathrm{LiCl}$ molar fraction of all samples was $6.25 \%$, and the $\mathrm{Mg} / \mathrm{Si}$ molar ratio was increased from 1:1.333 to 1.913:1. From Fig. 6, it may be seen that there two changes of the XRD pattern. Firstly, with the $\mathrm{Mg} / \mathrm{Si}$ molar ratio increased, the content of $\mathrm{Mg}_{4} \mathrm{Si}_{4} \mathrm{O}_{10}(\mathrm{OH})_{4} \cdot 2 \mathrm{H}_{2} \mathrm{O}$ phase increased. The intensity of hectorite characteristic diffraction (001) was decreased until to disappeared. In sample 3\#, because of the suitable of $\mathrm{Mg} / \mathrm{Si}$ molar ratio, the pure hectorite was obtained. When the $\mathrm{Mg} / \mathrm{Si}$ molar ratio increased to $1.143: 1$, the $\mathrm{Mg}(\mathrm{OH})_{2}$ phase was observed. The intensity of $\mathrm{Mg}(\mathrm{OH})_{2}$ characteristic diffraction was increased and then decreased. When the $\mathrm{Mg} / \mathrm{Si}$ molar ratio was $1.666: 1$ the $\mathrm{Mg}(\mathrm{OH})_{2}$ phase disappeared.

\section{Summary}

In this paper, the mechanism and process of synthesis hectorite were researched. When the $\mathrm{Mg} / \mathrm{Si}$ molar ratio was 1.333:1 and the molar fraction of $\mathrm{Li}$ was $6.25 \%$, the pure hectorite was obtained. When the $\mathrm{Mg} / \mathrm{Si}$ molar ratio increased to 2:1, the pure $\mathrm{Mg}_{4} \mathrm{Si}_{4} \mathrm{O}_{10}(\mathrm{OH})_{4} \cdot 2 \mathrm{H}_{2} \mathrm{O}$ phase was obtained, meanwhile $\mathrm{LiCl}$ did not react with other reactants. When the e $\mathrm{Mg} / \mathrm{Si}$ molar ratio was 1:1.333, the purification of hectorite was affected by the molar fraction of $\mathrm{LiCl}$ in the reactants. With the increment of the $\mathrm{Li}$ molar fraction, the $\mathrm{Li}_{2} \mathrm{SiO}_{3}$ phase was observed and its content increased obviously. The constitution of product was affected by the reaction temperature. When the 
temperature increased from $423 \mathrm{~K}$ to $463 \mathrm{~K}$, the $\mathrm{Mg}(\mathrm{OH})_{2}$ phase in the product decreased gradually and disappeared at last.

\section{Acknowledgments}

The authors are grateful for the financial support from the National Natural Science Foundation of China (reference 21106171) and Open fund of Key Laboratory of Comprehensive and Highly Efficient Utilization of Salt Lake Resources.

\section{References}

[1] Jinhe Sun, Yongzhong Jia, Yan Jing, Ying Yao, Jun Ma, Fabrication of multilayer pancakelike basic magnesium carbonate, Journal of Nanoscience and Nanotechnology, 14(2014) 8098-8101

[2] Suprakas Sinha Ray, Masami Okamoto, Polymer/layered silicate nanocomposites: a review from preparation to processing. Prog. Polym. Sci., 28(2003) 1539-1641.

[3] Jun Ma, Yongzhong Jia, Yan Jing, Ying Yao, Jinhe Sun, Synthesis and photocatalytic activity of $\mathrm{TiO}_{2}$-hectorite layer-by-layer thin films. Appl. Clay Sci., 47(2010) 433-437.

[4] Stephen F. Scully, Rabin Bissessur, Encapsulation of polymer electrolytes into hectorite. Appl. Clay Sci., 47(2010) 444-447.

[5] Duyuan Yue, Yan Jing, Jun Ma, Chenglong Xia, Xiaojie Yin, Yongzhong Jia, Removal of Neutral Red from aqueous solution by using nodified hectorite. Desalination, 267(2011) 9-15.

[6] Pieper H., Bosbach D., Panak P.J., Rabung T., Fanghanel T.. Eu(III) coprecipitation with the trioctahedral clay mineral hectorite. Clays Clay Miner., 54(2006) 45-53.

[7] Zhou, C.H., Du Z.X., Li X.N., Lu C.S., Ge Z.H.. Structure development of hectorite in hydrothermal crystallization synthesis process. Chin. J. Inorg. Chem., 21(2005) 1327-1332.

[8] Isabel Vicente, Pilar Salagre, Yolanda Cesteros, Francesc Guirado, Francisco Medina, Jesús E. Sueiras. Fast microwave synthesis of hectorite. Appl. Clay Sci., 43(2009) 103-107.

[9] Yao Ying, Jia Yongzhong, Jing Yan, Li Wu. The method of using natural brine to synthesize magnesium lithium silicate montmorillonite. Patent Number: ZL 200510096406.5.

[10] Xiaojie Yin, Yongzhong Jia, Ying Yao, Jun Ma. Phase diagram of $\mathrm{MgCl}_{2}-\mathrm{LiCl}-\mathrm{Na}_{2} \mathrm{SiO}_{3}-\mathrm{H}_{2} \mathrm{O}$ system at $200^{\circ} \mathrm{C}$ and synthesis of hectorite. Materials science forum, 688(2011) 201-206.

[11] Jun Ma, Yongzhong Jia, Yan Jing, Jinhe Sun, Ying Yao, Xiaohua Wang, Preparation and luminescence properties of lanthanide $\left(\mathrm{Eu}^{3+}, \mathrm{Sm}^{3+}\right)$ complexes and their hectorite-based composites, Spectrochimica Acta Part A, 75(2010) 855-858.

[12] Jun Ma, Yongzhong Jia, Yan Jing, Ying Yao, Jinhe Sun, Kinetics and thermodynamics of methylene blue adsorption by cobalt-hectorite composite, Dyes and Pigments, 93(2012) 1441-1446. 